\title{
Solubility and Solution Thermodynamics of Tylosin in Pure Solvents and Mixed Solvents at Various Temperatures
}

\author{
Yanmin Shen ${ }^{1,2^{*}}$ Wenju Liu ${ }^{1}$ Zehua Bao ${ }^{1}$ and Zhanhu Guo ${ }^{2 *}$
}

Thermodynamic data of drug is important to industrial design and industrial application. In this paper, solubility data of tylosin in pure solvents and acetone +water mixture solvents were experimentally determined from $279.75 \mathrm{~K}$ to $323.15 \mathrm{~K}$. The experiment results indicated that solubility of tylosin in pure solvents gradually decreased and followed this order: chloroform $>$ buty lacetate $>$ acetonitrile $>$ tetrahydrofuran $>$ acetone $>$ benzene $>$ n-butanol $>$ ethy lacetate $>$ n-propanol $>$ ethanol $>$ methanol $>$ water, and solubility gradually decreased with water increasing in water+acetone mixture solvents. Moreover, experimental solubility increased with temperature increasing except for water $\left(x_{c} \geqslant\right.$ 0.9281 ) +acetone mixture solvents. Thermodynamic models correlating solubility data showed that modified Apelblat model was litter better agreement than Van't Hoff model, Wilson model, NRTL model in pure solvents and C/R-K model, Jouyban Acree model in acetone+water solvents by ARD, RMSD and $\mathrm{R}^{2}$. Furthermore, thermodynamic properties for dissolution process of tylosin were calculated and discussed by modified Apelblat model paramaters.

Keywords: Tylosin; Solubility; Thermodynamics models; Dissolution process

Received 2 April 2019, Accepted 15 June 2019

DOI: $10.30919 /$ esmm5f233

\section{Introduction}

Tylosin (CAS:1401-69-0, Fig. 1) is a kind of antibiotic drugs that are greatly applied livestock not only to treat disease, but also to improve the feed utilization as feed additive. ${ }^{1-3}$ Because tylosin is a medium spectrum antibiotic to treat infections caused by most Gram-positive bacteria, mycoplasmas, some Gram-negative bacteria, Chlamydia, and to increase the rates of weight gain and improve the feed efficiency of companion animals, such as cattle, chicken, turkey, and swine ${ }^{1-3}$. Therfore, investigations and research thermodynamic properties of drugs are vital to understand nature of molecular interactions and explore new fields. The solid-liquid equilibrium solubility data of drugs plays an important role separation and purification for process choosing in industry application. In this research, the solubility of tylosin were experimentally determined in chloroform, butyl acetate, acetonitrile, tetrahydrofuran, acetone, benzene, n-butanol, ethyl acetate, n-propanol, ethanol, methanol, water and acetone+water mixture solvents, and were correlated with modified Apelblat model, Van't Hoff model, Wilson model, NRTL model, C/R-K model and Jouyban-Acree model from $279.75 \mathrm{~K}$ to $323.15 \mathrm{~K}$. Furthermore, $\Delta_{\text {sol }} H^{o}, \Delta_{\text {sol }} S^{o}$ and $\Delta_{s o l} G^{o}$ for the dissolution processes of tylosin were calculated by modified Apelblat model parameters.

'College of Chemistry ,Chemical and Environmental Engineering, Henan University of Technology, Zhengzhou 450001, China 2Integrated Composites Laboratory (ICL), Department of Chemical \& Biomolecular Engineering, University of Tennessee, Knoxville, TN 37966, USA

*E-mail: shenym1978@126.com; zguo10@utk.edu

\section{Experimental}

\subsection{Materials}

In the paper, tylosin was supplied from Ningxia Tairui Pharmaceutical Co.Ltd., China and purified before use by dilution crystallization method. Purity of tylosin was determined by HPLC (type Agilent 1200, Agilent Technologies).All solvents are analytical grade without further detection. Resources information were presented in Table 1.

\subsection{Thermal analysis}

The DSC measurements were operated for tylosin in a nitrogen atmosphere with a differential scanning calorimeter (NETZSCH, STA409PC). Tylosin sample was scanned from $270.6 \mathrm{~K}$ to $772.9 \mathrm{~K}$ at heating rate of $5 \mathrm{~K} \cdot \mathrm{min}^{-1}$.

\subsection{Characterization}

The powder X-ray diffraction equipment (Bruker D8 Advance) was

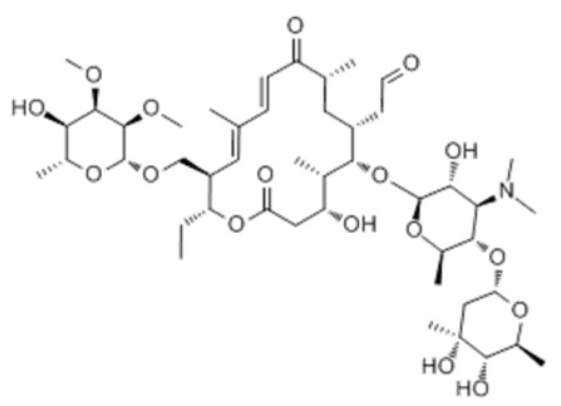

Fig. 1 Molecular structure of tylosin. 
used to collect samples data and to ensure crystal form of samples. Diffraction angle was range from $2^{\circ}$ to $50^{\circ}(2 \theta)$ and a scanning speed of $5^{\circ} \mathrm{min}^{-1}$ with a current of $40 \mathrm{~mA}$ and a voltage of $40 \mathrm{kV}$.

\subsection{Solubility determination}

In this work, the gravimetric method was adopted to determine solubility of tylosin from $279.75 \mathrm{~K}$ to $323.15 \mathrm{~K}$ at the pressure of 0.1 $\mathrm{MPa}{ }^{45}$ Firstly, the excess drug of tylosin sample and a certain amount of selected solvents was set into the cylindrical double-jacketed glass container with a designed temperature $( \pm 0.05 \mathrm{~K})$. The glass container was kept a designed temperature with water circulating. The prepared mixed solution was stirred more than $12 \mathrm{~h}$ to reach dissolution equilibrium. $^{45}$ Then, solid-liquid solution was set to stop stirring, precipitate and stratify $12 \mathrm{~h}$. Next, $5 \mathrm{~mL}$ sampling was extracted from upper liquid and placed in double dish, weighed and set into a vacuum oven to dry for $12 \mathrm{~h}$ at $323.15 \mathrm{~K}$. Lastly, Experimental solubility were measured at least three times to reduce mistakes. The solubility $x$ of tylosin could be calculated by following equation:

$$
\begin{aligned}
& x=\frac{m_{1} / M_{1}}{m_{1} / M_{1}+m_{2} / M_{2}} \\
& x=\frac{m_{1} / M_{1}}{m_{1} / M_{1}+m_{B} / M_{B}+m_{C} / M_{C}} \\
& x_{C}=\frac{m_{B 0} / M_{B}}{m_{B 0} / M_{B}+m_{C 0} / M_{C}}
\end{aligned}
$$

where $m_{1}$ and $m_{2}$ (or $m_{B}$ and $m_{C}$ ) stand for the mass of tylosin and the mass of solvents, respectively. $M_{1}$ and $M_{2}$ (or $M_{B}$ and $M_{C}$ ) are the molar masses of tylosin and solvent, respectively. $x_{c}$ is initial composition of water in acetone+water mixture solvent under condition of without tylosin.

\section{Results and discussion}

\subsection{DSC and XRD analysis}

From DSC curve, It was shown that there was a bigger and wider peak at $547.41 \mathrm{~K}$, this revealed that the drug of tylosin had not fixed melting point and decomposed before melting temperature, Because tylosin had larger molecular weight and complex structure from Fig. 1. So, the thermal decomposition temperature was $547.41 \mathrm{~K}$ and enthalpy of fusion $H_{\text {fis }}$ was $88.9 \mathrm{~kJ} \cdot \mathrm{mol}^{-1}$ from Fig. 2.

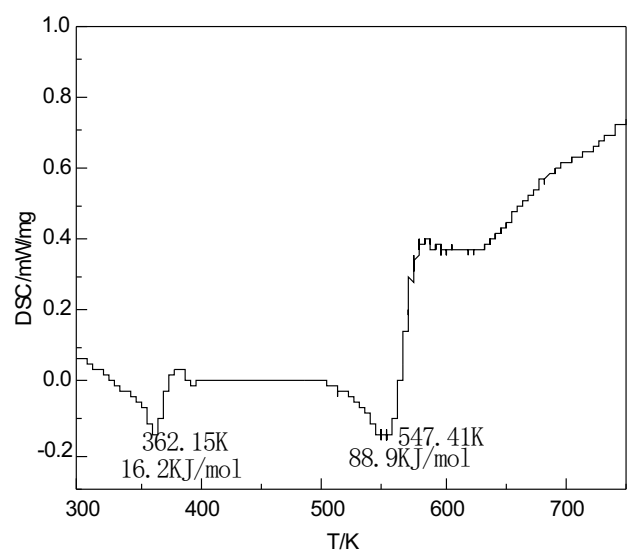

Fig. 2 DSC curve.

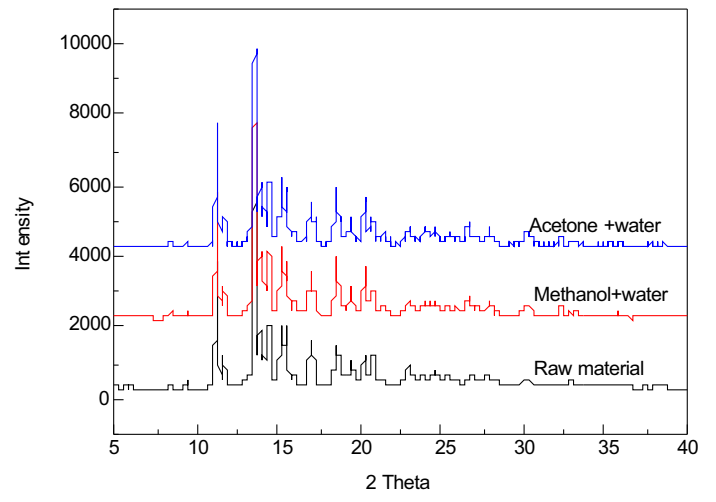

Fig. 3 XRD pattern of before and after recrystallization of tylosin.

Table 1 Description of materials used in this paper.

\begin{tabular}{lllc}
\hline Chemical name & Formula & Source & Mass fraction purity \\
\hline Tylosin & $\mathrm{C}_{46} \mathrm{H}_{77} \mathrm{NO}_{17}$ & Ningxia Tairui Pharmaceutical & $\geq 0.99$ \\
Methanol (AR) & $\mathrm{CH}_{3} \mathrm{OH}$ & Tianjin Wind Ship Chemical & $\geq 0.995$ \\
Ethanol (AR) & $\mathrm{C}_{2} \mathrm{H}_{5} \mathrm{OH}$ & Tianjin Wind Ship Chemical & $\geq 0.997$ \\
n-Propanol (AR) & $\mathrm{C}_{3} \mathrm{H}_{7} \mathrm{OH}$ & Tianjin Wind Ship Chemical & $\geq 0.998$ \\
n-Butanol(AR) & $\mathrm{C}_{4} \mathrm{H}_{9} \mathrm{OH}$ & Tianjin Wind Ship Chemical & $\geq 0.995$ \\
Acetone (AR) & $\mathrm{C}_{4} \mathrm{H}_{6} \mathrm{O}$ & Tianjin Wind Ship Chemical & $\geq 0.99$ \\
Chloroform (AR) & $\mathrm{CHCl}_{3}$ & Tianjin Wind Ship Chemical & $\geq 0.99$ \\
Acetonitrile (AR) & $\mathrm{C}_{2} \mathrm{H}_{3} \mathrm{~N}$ & Tianjin Kermel Chemical & $\geq 0.995$ \\
Butyl acetate (AR) & $\mathrm{C}_{6} \mathrm{H}_{12} \mathrm{O}_{2}$ & Tianjin Kermel Chemical & $\geq 0.99$ \\
Ethyl acetate (AR) & $\mathrm{C}_{4} \mathrm{H}_{8} \mathrm{O}_{2}$ & Tianjin Kermel Chemical & $\geq 0.995$ \\
Benzene (AR) & $\mathrm{C}_{6} \mathrm{H}_{6}$ & Tianjin Wind Ship Chemical & $\geq 0.995$ \\
Tetrahydrofuran (AR) & $\mathrm{C}_{4} \mathrm{H}_{8} \mathrm{O}$ & Tianjin Wind Ship Chemical & $\geq 0.995$ \\
\hline
\end{tabular}

${ }^{\mathrm{a}} \mathrm{AR}$ means analytical reagent. 
Fig. 3 presented the XRD pattern of the crystal. It could be seen that the morphologies of tylosin was not changed after recrystallization according with comparing with the powder diffraction spectrum of before and after recrystallization of tylosin.

\subsection{Solubility data}

The determination solubility data of tylosin were shown in Tables 2-3 and correlated Figs. 4-6 in pure solvents and acetone+water binary solvents systems with the temperature range from $279.75-323.15 \mathrm{~K}$. From Table 2 and Fig. 4, the solubility values of tylosin increased with increasing temperature except for water in pure solvents, the solubility gradually decreased and followed this order: chloroform $>$ butyl acetate $>$ acetonitrile $>$ tetrahydrofuran $>$ acetone $>$ benzene $>$ n-butanol $>$ Ethyl acetate $>$ n-propanol $>$ ethanol $>$ methanol $>$ water. According to

Table 2 The measured and calculated mole fraction solubility of tylosin in different solvents from 279.75 to $323.15 \mathrm{~K}$.

\begin{tabular}{|c|c|c|c|c|c|c|c|c|c|c|c|}
\hline \multirow{2}{*}{$\mathrm{T} / \mathrm{K}$} & \multirow{2}{*}{$10^{2} x_{e x p}$} & \multicolumn{4}{|c|}{$10^{2} x_{\text {cal }}$} & \multirow{2}{*}{$\mathrm{T} / \mathrm{K}$} & \multirow{2}{*}{$10^{2} x_{e x p}$} & \multicolumn{4}{|c|}{$10^{2} x_{c a l}$} \\
\hline & & Apel & Van't & Wilson & NRNL & & & Apel & Van 't & Wilson & NRNL \\
\hline & \multicolumn{5}{|c|}{ Methanol } & \multicolumn{6}{|c|}{ Ethanol } \\
\hline 280.25 & 0.4486 & 0.4536 & 0.4195 & 0.3101 & 0.4637 & 281.75 & 0.6949 & 0.7228 & 0.6687 & 0.5073 & 0.6444 \\
\hline 287.05 & 0.6448 & 0.5987 & 0.576 & 0.5146 & 0.6901 & 287.95 & 0.8668 & 0.9405 & 0.8991 & 0.8768 & 0.8936 \\
\hline 292.85 & 0.7529 & 0.7576 & 0.7462 & 0.8656 & 0.718 & 293.45 & 1.1856 & 1.185 & 1.1569 & 1.2076 & 1.1321 \\
\hline 297.85 & 0.9183 & 0.9271 & 0.9252 & 1.1682 & 0.8844 & 298.05 & 1.3738 & 1.4348 & 1.4183 & 1.6681 & 1.4277 \\
\hline 302.55 & 1.0885 & 1.1199 & 1.1251 & 1.4968 & 1.0527 & 303.05 & 1.7245 & 1.7631 & 1.7574 & 2.0835 & 1.7667 \\
\hline 307.15 & 1.3308 & 1.3462 & 1.3546 & 1.6775 & 1.3409 & 307.85 & 2.1497 & 2.1448 & 2.145 & 2.4057 & 2.1363 \\
\hline 312.35 & 1.6099 & 1.6557 & 1.66 & 1.9058 & 1.632 & 312.55 & 2.581 & 2.5938 & 2.5918 & 2.7484 & 2.589 \\
\hline 317.35 & 2.0405 & 2.018 & 2.0057 & 1.7289 & 2.085 & 317.45 & 3.1633 & 3.1566 & 3.1381 & 2.9079 & 3.102 \\
\hline 321.65 & 2.3784 & 2.3902 & 2.3491 & 1.7092 & 2.3397 & 322.55 & 3.764 & 3.8649 & 3.8059 & 3.1401 & 3.7946 \\
\hline \multicolumn{6}{|c|}{ n-Propanol } & \multicolumn{6}{|c|}{ n-Butanol } \\
\hline 279.75 & 2.0177 & 2.0553 & 1.9293 & 1.7018 & 2.0176 & 279.75 & 1.3455 & 1.285 & 1.3618 & 1.1597 & 1.2947 \\
\hline 287.65 & 2.328 & 2.3672 & 2.3075 & 2.3258 & 2.3139 & 287.75 & 1.7681 & 1.7683 & 1.8329 & 1.8858 & 1.8113 \\
\hline 293.05 & 2.5884 & 2.6178 & 2.5934 & 2.7118 & 2.5418 & 293.05 & 2.1935 & 2.1544 & 2.2118 & 2.3448 & 2.2088 \\
\hline 297.35 & 2.7577 & 2.8421 & 2.8375 & 3.2361 & 2.8526 & 297.35 & 2.5941 & 2.5095 & 2.5634 & 2.7083 & 2.5694 \\
\hline 302.55 & 3.1517 & 3.1464 & 3.1529 & 3.2107 & 3.0045 & 302.65 & 3.1376 & 3.0016 & 3.0569 & 3.1612 & 3.067 \\
\hline 307.45 & 3.366 & 3.4701 & 3.4708 & 3.8773 & 3.4998 & 307.15 & 3.5062 & 3.4688 & 3.5329 & 3.8061 & 3.5953 \\
\hline 312.65 & 3.8096 & 3.8579 & 3.8306 & 3.8055 & 3.7753 & 312.05 & 4.1351 & 4.0311 & 4.1163 & 4.1614 & 4.1488 \\
\hline 317.15 & 4.154 & 4.2348 & 4.1611 & 3.9793 & 4.1805 & 316.35 & 4.7012 & 4.5718 & 4.6887 & 4.5181 & 4.6882 \\
\hline 321.65 & 4.5785 & 4.6545 & 4.5096 & 3.938 & 4.5512 & 321.15 & 5.3616 & 5.2288 & 5.4 & 4.9444 & 5.3461 \\
\hline \multicolumn{6}{|c|}{ Chloroform } & \multicolumn{6}{|c|}{ Acetonitrile } \\
\hline 280.25 & 3.2637 & 3.3176 & 3.2157 & 2.8894 & 3.3192 & 281.85 & 5.7934 & 5.8306 & 5.6223 & 5.2853 & 5.6922 \\
\hline 287.05 & 4.1595 & 4.0205 & 4.029 & 3.8975 & 3.9472 & 289.35 & 6.1877 & 6.2474 & 6.1703 & 6.5079 & 6.2455 \\
\hline 292.85 & 4.8502 & 4.7406 & 4.843 & 5.1344 & 4.8227 & 292.85 & 6.4903 & 6.4659 & 6.4335 & 6.3232 & 6.3867 \\
\hline 297.85 & 5.4514 & 5.4667 & 5.6431 & 6.4615 & 5.8135 & 298.65 & 6.8681 & 6.8637 & 6.8799 & 7.0578 & 6.8583 \\
\hline 302.55 & 6.4828 & 6.2523 & 6.4853 & 6.9455 & 6.3689 & 303.45 & 7.182 & 7.2289 & 7.2585 & 7.8071 & 7.3157 \\
\hline 307.15 & 7.453 & 7.1318 & 7.4006 & 7.6318 & 7.1949 & 307.95 & 7.618 & 7.6028 & 7.6207 & 7.6391 & 7.5888 \\
\hline 312.35 & 8.4904 & 8.2772 & 8.5517 & 8.7068 & 8.5211 & 313.25 & 7.9915 & 8.085 & 8.0562 & 8.5663 & 8.1968 \\
\hline 317.35 & 9.6805 & 9.5525 & 9.7832 & 9.5157 & 9.9105 & 318.25 & 8.4851 & 8.5845 & 8.4754 & 8.6603 & 8.6239 \\
\hline 321.65 & 11.064 & 10.805 & 10.947 & 9.6175 & 10.949 & 322.65 & 9.0895 & 9.0624 & 8.8508 & 7.9343 & 8.7809 \\
\hline \multicolumn{6}{|c|}{ Butyl acetate } & \multicolumn{6}{|c|}{ Ethyl acetate } \\
\hline 281.95 & 6.5687 & 6.4234 & 6.4199 & 6.0072 & 6.4454 & 282.05 & 3.7167 & 3.7369 & 3.6229 & 2.8413 & 3.7545 \\
\hline 289.35 & 6.9708 & 6.7715 & 6.9524 & 6.8768 & 6.9065 & 289.45 & 3.8761 & 3.8556 & 3.8441 & 3.428 & 3.8369 \\
\hline 292.75 & 7.1825 & 6.957 & 7.2019 & 7.17 & 7.1248 & 292.65 & 3.9461 & 3.9205 & 3.9402 & 3.7296 & 3.8987 \\
\hline 298.75 & 7.5316 & 7.3259 & 7.6493 & 8.072 & 7.6306 & 298.85 & 4.0908 & 4.0698 & 4.1271 & 4.332 & 4.0557 \\
\hline
\end{tabular}


Table 2 continued

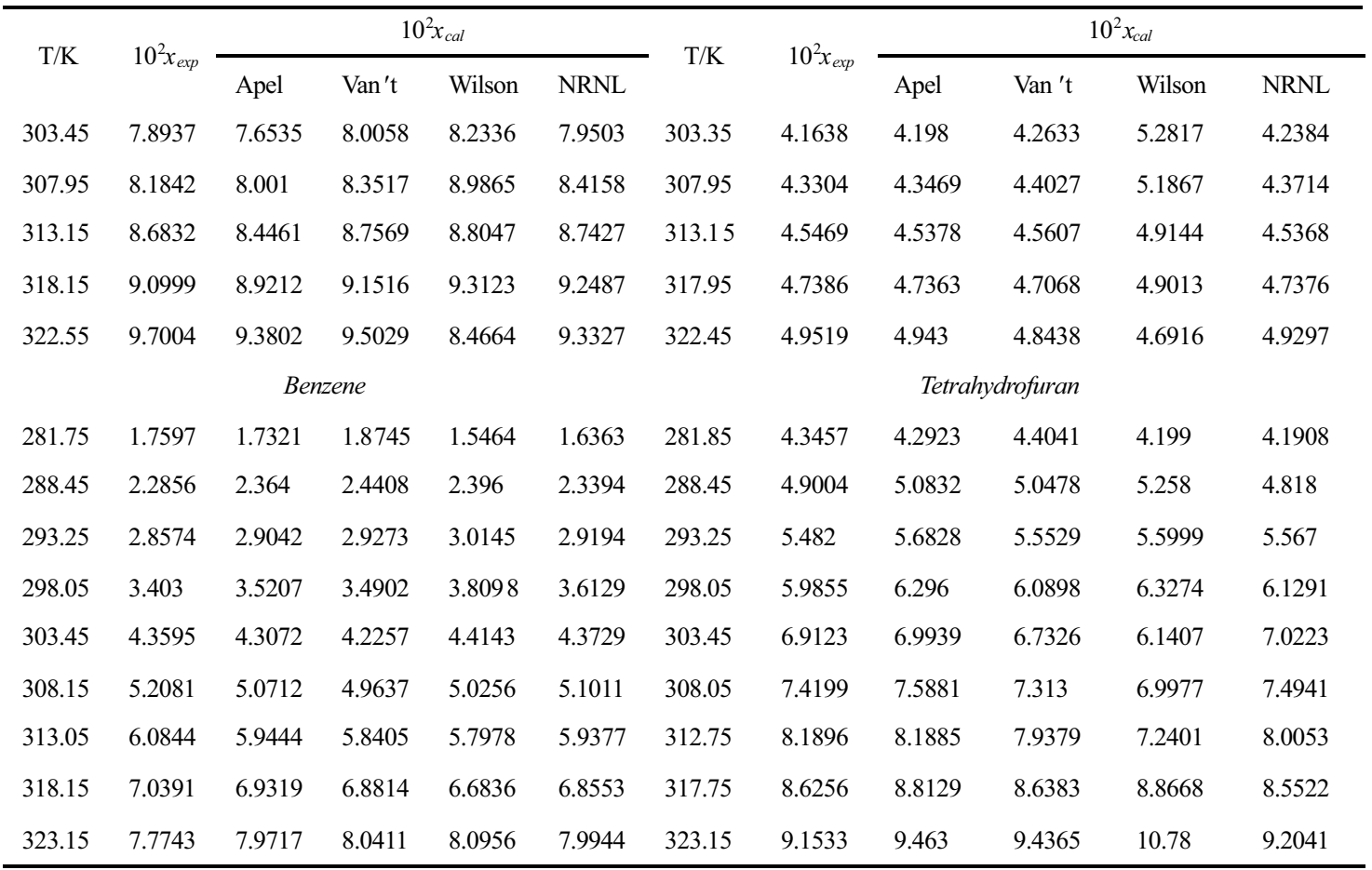

${ }^{a} x_{\text {exp }}$ and $x_{\text {cal }}$ are experimental and calculated mole fraction of tylosin in solvents;

Standard uncertainties of temperature is $u(\mathrm{~T})=0.05 \mathrm{~K}$, standard uncertainty of pressure is $u(\mathrm{P})=0.3 \mathrm{kPa}$; relative standard uncertainty of solubility measurement is $u_{r}(x)=2 \%$.

Table 3 The measured and calculated mole fraction solubility of tylosin acetone $\left(1-x_{c}\right)+$ water $\left(x_{c}\right)$ solvents.

\begin{tabular}{lllllllll}
\hline $\mathrm{T} / \mathrm{K}$ & $100 x_{\text {exp }}$ & $100 x_{\text {cal }}^{\text {Apel }}$ & $\mathrm{T} / \mathrm{K}$ & $100 x_{\text {exp }}$ & $100 x_{\text {cal }}^{\text {Apel }}$ & $\mathrm{T} / \mathrm{K}$ & $100 x_{\text {exp }}$ & $100 x_{\text {cal }}^{\text {Apel }}$ \\
\hline & $x_{c}=0.0000$ & & & $x_{c}=0.1955$ & & & $x_{c}=0.3629$ \\
281.75 & 2.866 & 2.8253 & 281.85 & 2.696 & 2.7794 & 281.85 & 2.521 & 2.6199 \\
287.95 & 3.256 & 3.337 & 288.65 & 3.187 & 3.2617 & 288.65 & 2.979 & 3.0768 \\
293.45 & 4.014 & 3.8525 & 293.35 & 3.826 & 3.6354 & 293.35 & 3.423 & 3.4064 \\
298.05 & 4.273 & 4.3322 & 298.15 & 4.175 & 4.0541 & 298.15 & 3.857 & 3.7516 \\
302.85 & 4.771 & 4.884 & 302.95 & 4.51 & 4.5134 & 302.95 & 4.173 & 4.1027 \\
307.75 & 5.297 & 5.5054 & 307.95 & 4.873 & 5.0382 & 307.85 & 4.535 & 4.4644 \\
312.65 & 5.997 & 6.1901 & 312.65 & 5.544 & 5.5783 & 312.55 & 4.839 & 4.8115 \\
316.75 & 6.883 & 6.8152 & 317.65 & 6.186 & 6.2063 & 317.55 & 5.117 & 5.1780 \\
323.25 & 7.898 & 7.9114 & 322.05 & 6.873 & 6.8080 & 321.85 & 5.421 & 5.4885 \\
& $x_{c}=0.4466$ & & & & & & $x_{c}=0.6827$ & \\
279.95 & 2.287 & 2.2910 & 281.85 & 1.977 & 1.9773 & 281.45 & 0.906 & 0.8989 \\
287.85 & 2.654 & 2.6740 & 288.65 & 2.296 & 2.2747 & 288.05 & 0.995 & 1.0291 \\
293.25 & 3.001 & 2.9477 & 293.35 & 2.482 & 2.4910 & 293.75 & 1.149 & 1.1460 \\
297.95 & 3.169 & 3.1925 & 298.15 & 2.703 & 2.7201 & 298.55 & 1.26 & 1.2470 \\
302.85 & 3.452 & 3.4529 & 302.85 & 2.931 & 2.9518 & 302.95 & 1.359 & 1.3411 \\
307.65 & 3.686 & 3.7122 & 307.75 & 3.207 & 3.2003 & 307.85 & 1.478 & 1.4471
\end{tabular}




\begin{tabular}{|c|c|c|c|c|c|c|c|c|}
\hline $\mathrm{T} / \mathrm{K}$ & $100 x_{\exp }$ & $100 x_{\text {cal }}^{\text {Appl }}$ & $\mathrm{T} / \mathrm{K}$ & $100 x_{\text {exp }}$ & $100 x_{\text {cal }}^{\text {Apel }}$ & $\mathrm{T} / \mathrm{K}$ & $100 x_{\text {exp }}$ & $100 x_{\text {cal }}^{\text {Apel }}$ \\
\hline 312.65 & 3.975 & 3.9854 & 312.45 & 3.487 & 3.4444 & 313.15 & 1.581 & 1.5624 \\
\hline 316.75 & 4.247 & 4.2109 & 317.45 & 3.706 & 3.7094 & 318.05 & 1.637 & 1.6690 \\
\hline \multirow[t]{2}{*}{322.85} & 4.534 & 4.5473 & 321.65 & 3.922 & 3.9355 & 322.95 & 1.779 & 1.7750 \\
\hline & \multicolumn{3}{|l|}{$x_{c}=0.7634$} & \multicolumn{2}{|c|}{$x_{c}=0.8288$} & \multicolumn{3}{|c|}{$x_{c}=0.8827$} \\
\hline 281.45 & 0.627 & 0.6391 & 281.55 & 0.488 & 0.4930 & 281.15 & 0.201 & 0.1980 \\
\hline 288.05 & 0.736 & 0.7409 & 288.05 & 0.584 & 0.5755 & 288.05 & 0.235 & 0.2365 \\
\hline 293.75 & 0.846 & 0.8318 & 293.75 & 0.646 & 0.6531 & 293.75 & 0.266 & 0.2712 \\
\hline 298.55 & 0.935 & 0.9095 & 298.55 & 0.72 & 0.7222 & 297.35 & 0.289 & 0.2943 \\
\hline 302.95 & 0.981 & 0.9810 & 302.95 & 0.786 & 0.7882 & 302.95 & 0.337 & 0.3322 \\
\hline 307.85 & 1.05 & 1.0604 & 307.65 & 0.858 & 0.8614 & 307.45 & 0.371 & 0.3641 \\
\hline 312.95 & 1.166 & 1.1420 & 312.85 & 0.966 & 0.9453 & 312.75 & 0.413 & 0.4032 \\
\hline 317.95 & 1.222 & 1.2202 & 317.75 & 1.043 & 1.0268 & 317.55 & 0.437 & 0.4400 \\
\hline \multirow[t]{2}{*}{322.85} & 1.291 & 1.2945 & 322.55 & 1.089 & 1.1086 & 322.35 & 0.473 & 0.4779 \\
\hline & \multicolumn{3}{|l|}{$x_{c}=0.9281$} & \multicolumn{2}{|c|}{$x_{c}=0.9667$} & \multicolumn{3}{|c|}{$x_{c}=1$} \\
\hline 281.95 & 0.12 & 0.1195 & 281.95 & 0.0492 & 0.0502 & 281.95 & 0.0192 & 0.0194 \\
\hline 288.45 & 0.0992 & 0.1010 & 288.45 & 0.0431 & 0.0421 & 288.45 & 0.0147 & 0.0147 \\
\hline 293.25 & 0.0922 & 0.0906 & 293.25 & 0.0381 & 0.0372 & 293.25 & 0.0123 & 0.0121 \\
\hline 298.05 & 0.0842 & 0.0824 & 298.05 & 0.034 & 0.0330 & 298.05 & 0.0102 & 0.0101 \\
\hline 303.25 & 0.0744 & 0.0754 & 303.15 & 0.0299 & 0.0292 & 303.15 & 0.0087 & 0.0084 \\
\hline 307.95 & 0.068 & 0.0703 & 307.85 & 0.0257 & 0.0261 & 307.75 & 0.0074 & 0.0071 \\
\hline 312.65 & 0.067 & 0.0663 & 312.55 & 0.0238 & 0.0235 & 312.45 & 0.0057 & 0.0061 \\
\hline 317.75 & 0.0635 & 0.0628 & 317.75 & 0.0202 & 0.0210 & 317.75 & 0.0049 & 0.0052 \\
\hline 322.65 & 0.0602 & 0.0603 & 322.35 & 0.0186 & 0.0190 & 322.15 & 0.0043 & 0.0045 \\
\hline
\end{tabular}

${ }^{a} x_{\text {exp }}$ and $x_{c a l}$ are experimental and calculated mole fraction of tylosin in solvents;

$x_{c}$ is initial composition of water in acetone+water mixture solvent under condition of without tylosin;

Standard uncertainties of temperature is $u(\mathrm{~T})=0.05 \mathrm{~K}$, standard uncertainty of pressure is $u(\mathrm{P})=0.3 \mathrm{kPa}$; relative standard uncertainty of solubility measurement is $u_{r}(x)=2 \%$.

the thermodynamics of solutions, solubility of tylosin in solvent are affected many factors that are solvent polarity, the same molecules selfassociation and the different molecules cross-association. ${ }^{6-7}$ The polarity of tylosin was weaker by Fig. 1. According with the principle of "like dissolves like," tylosin dissolved highly in poorer polarity solvents like chloroform, butyl acetate and acetone than in stronger polarity solvents like water, methanol and ethanol. Especially, solubility of tylosin was confirmed to decrease with increasing temperature and was consistent with reference in water.

From Table 3 and Fig. 5, in acetone+water mixture solvents, solubility values of tylosin increased with the increasing temperature when $x_{c}$ was less than 0.9281 , and decreased with the increasing mole fraction of water in mixture solvents. Because solubility was affected obviously and sensitive with water content. All factors influencing separation ways of tylosin could be considered as temperature, toxicity, cost, source of solvent and operability of purification process. Dilution crystallization process will be selected to separate and purify for tylosin with acetone+water solvents system in industry according with solubility data measured.

\subsection{Solubility modeling}

\subsubsection{Modified Apelblat model}

The modified Apelblat model is widely applied and well-correlated the relation between solubility data and different temperatures, which is described as following equation: ${ }^{9,10}$

$$
\ln x=A+\frac{B}{T / K}+C \ln (T / K)
$$

where $x$ is experimental determination mole fraction solubility, $T$ is thermodynamic absolute temperature. $A, B$ and $C$ are three model parameters in Eq. (4) and are listed in the Table 4 and Table 6. $A R D$ is named corresponding average absolute deviation, and $R M S D$ is named root mean square deviations, $A R D$ and $R M S D$ are calculated with Eq. (5) and Eq. (6) :

$$
A R D=\frac{\left(\sum_{i=1}^{n} \frac{\left|x_{i, c a l}-x_{i}\right|}{x_{i}}\right)}{n}
$$


The root-mean-square deviations $(R M)$ is defined as follows:

$$
R M S D=\left[\sum_{i=1}^{n} \frac{\left(x_{i, c a l}-x_{i}\right)^{2}}{n}\right]^{1 / 2}
$$

where $x_{\text {i.cal }}$ and $x_{i}$ represent the calculated and determination values, $n$ is total times of experimental points. ARD and RMSD are presented in Tables 4-8.

\subsubsection{Vant Hoff model}

Based on thermodynamic principles of the solid-liquid equilibrium ${ }^{13,14}$, the Van't Hoff model is considered as the simplest equation describing relationship of solubility and temperature.

$$
\ln x=a+\frac{b}{T / K}
$$

In Eq. (7), the two model parameters of $a$ and $b$ are gained from fitting results by solubility data and are shown in Table 4 .

\subsubsection{Wilson model}

According to the theory of phase equilibrium, the fugacity of solid phase and liquid phase equals when solid sample in solvent reaches at the state of dissolving equilibrium. The Wilson model is organized and simplified into binary form. ${ }^{15,16}$

$$
\begin{gathered}
\ln \gamma_{1}=-\ln \left(x_{1}+\Lambda_{12} x_{2}\right)+x_{2}\left[\frac{\Lambda_{12}}{x_{1}+\Lambda_{12} x_{2}}-\frac{\Lambda_{21}}{x_{2}+\Lambda_{21} x_{1}}\right] \\
\ln \gamma_{2}=-\ln \left(x_{2}+\Lambda_{21} x_{1}\right)+x_{1}\left[\frac{\Lambda_{21}}{x_{2}+\Lambda_{21} x_{1}}-\frac{\Lambda_{12}}{x_{1}+\Lambda_{12} x_{2}}\right] \\
\Lambda_{12}=\frac{V_{2}}{V_{1}} \exp \left(-\frac{\lambda_{12}-\lambda_{11}}{R T}\right)=\frac{V_{2}}{V_{1}} \exp \left(-\frac{\Delta \lambda_{12}}{R T}\right) \\
\Lambda_{21}=\frac{V_{1}}{V_{2}} \exp \left(-\frac{\lambda_{21}-\lambda_{22}}{R T}\right)=\frac{V_{1}}{V_{2}} \exp \left(-\frac{\Delta \lambda_{21}}{R T}\right)
\end{gathered}
$$

where $V_{1}$ and $V_{2}$ represent mole volumes of solute and pure solvent, $\mathrm{m}^{3} \cdot \mathrm{mol}^{-1}$, the two parameters of $\Delta \lambda_{12}$ and $\Delta \lambda_{21}$ stand for energy of cross interaction between different molecule, $\mathrm{J} \cdot \mathrm{mol}^{-1}$ and are shown in Table 5 .

\subsubsection{NRTL model}

Another about activity coefficient equal is expressed as NRTL model, where three parameters exist in binary interaction, NRTL model can be organized and simplified into the following equations. ${ }^{16,17,18}$

$$
\begin{gathered}
\ln \gamma_{1}=x_{2}^{2}\left[\frac{\tau_{21} G_{21}^{2}}{\left(x_{1}+x_{2} G_{21}\right)^{2}}+\frac{\tau_{12} G_{12}}{\left(x_{2}+x_{1} G_{12}\right)^{2}}\right] \\
\tau_{12}=\frac{\left(g_{12}-g_{11}\right)}{R T}=\frac{\Delta g_{12}}{R T} \\
\tau_{21}=\frac{\left(g_{21}-g_{22}\right)}{R T}=\frac{\Delta g_{21}}{R T} \\
G_{12}=\exp \left(-\alpha \tau_{12}\right), G_{21}=\exp \left(-\alpha \tau_{21}\right)
\end{gathered}
$$

where $\Delta \mathrm{g}_{12}$ and $\Delta \mathrm{g}_{21}$ are considered as model constants and stand for energy of cross interaction between different molecules, $\mathrm{Jmol}^{-1} ; \alpha$ is a parameter related to non-randomness of a solution; all of parameters are presented in Table 5.

\subsubsection{C/R-K model}

At a constant temperature, $\mathrm{C} / \mathrm{R}-\mathrm{K}$ model is applied as the most appropriate and direct model to build the inherently complex relationship between composition and solubility in binary mixture solvents. The model can be simplify and deduced to Eq.(16) in $\operatorname{ref}^{19}$ :

$$
\ln x=B_{0}+B_{1} x_{c}+B_{2} x_{c}^{2}+B_{3} x_{c}^{3}+B_{4} x_{c}{ }^{4}
$$

where there are five model parameters from $B_{0}$ to $B_{4}$ in Eq. $(16) ; x_{c}$ represents initial composition of water in mixture solvent; $B_{0,} B_{l}, B_{2}, B_{3}$ and $B_{4}$ are presented in Table 7 .

\subsubsection{Jouyban Acree model}

Jouyban Acree model ${ }^{19}$ is frequently applied another semi-empirical equation to correlate solubility data and temperature in mixtures solvent, which is described to Eq.(17) as follows:

$$
\ln \left(x_{A}\right)=x_{B} \ln \left(x_{A}\right)_{B}+x_{C} \ln \left(x_{A}\right)_{C}+x_{B} x_{C} \sum_{i=0}^{2} \frac{J_{i}\left(x_{B}-x_{C}\right)^{i}}{T}
$$

$\ln \left(x_{A}\right)_{B}$ and $\ln \left(x_{A}\right)_{C}$ can be expressed with modified Apelblat model as Eq. (18) and Eq. (19) Eq.(17) can be simplified to Eq. (20) by the combination of Eq. (17), Eq. (18) and Eq. (19).$^{20-23}$

$$
\begin{gathered}
\ln \left(x_{A}\right)_{B}=a_{1}+\frac{b_{1}}{T}+c_{1} \ln T \\
\ln \left(x_{A}\right)_{C}=a_{2}+\frac{b_{2}}{T}+c_{2} \ln T \\
\ln (x)=A_{1}+\frac{A_{2}}{T}+A_{3} \ln T+A_{4} x_{c}+A_{5} \frac{x_{c}}{T}+A_{6}\left(\frac{x_{c}}{T}\right)^{2}+A_{7}\left(\frac{x_{c}}{T}\right)^{3} \\
+A_{8}\left(\frac{x_{c}}{T}\right)^{4}+A_{9} x_{c} \ln T
\end{gathered}
$$

where $x$ represents solubility data of tylosin in acetone+water solvents, $x$ represents initial composition of water in mixture solvent; there are nine model parameters from $A_{l}$ to $A_{9}$, All of parameters are presented in Table 8, together with $R^{2}$.

The solubility values of tylosin in pure solvents were fitted by modified Apelblat model, Vant Hoff model, Wilson model and NRTL model, respectively. The computed solubility values with the modified Apelblat model are plotted in Fig. 4. Comparing of the total $A R D$, $R M S D$ and $R^{2}$ from Tables 4-5. Tables 4-5 showed that $R^{2}$ values varied more than $0.993, A R D$ and $R M S D$ values were less than $2.69 \%$ and $2.2 \times 10^{-3}$ by modified Apelblat model. It could be said that the modified Apelblat model was little better than other three models. At the same time, the solubility values of tylosin in acetone+water solvents were fitted by modified Apelblat model, C/R-K model and Apelblat-Jouyban Acree model, respectively. The computed solubility values are plotted with the modified Apelblat model in Fig. 5 and with the C/R-K model in Fig. 6. Comparing of the total $A R D, R M S D$ and $R^{2}$ from Tables 6-8. It indicated that $R^{2}$ values varied between 0.991 and 0.999 from modified Apelblat model, $A R D$ and $R M S D$ values from modified Apelblat model were less than $3.11 \%$ and $1.12 \times 10^{-3}$ and less than from C/R-K model and Apelblat-Jouyban Acree model. These data in Tables 4-8 indicated that modified Apelblat model can litter better agree with solubility data of tylosin and provides reliable results for data prediction in pure solvents and in acetone+water solvents at varying temperature between $279.75 \mathrm{~K}$ and $323.15 \mathrm{~K}$ under the pressure of $0.1 \mathrm{MPa}$. 
Table 4 Parameters of the modified Apelblat model and Van't Hoff model for tylosin in pure solvent.

\begin{tabular}{lllllllllllll}
\hline \multirow{2}{*}{ Solvents } & \multicolumn{1}{c}{ Modified Apelblat model } & \multicolumn{5}{c}{ Van't Hoff model $^{\prime}$} \\
\cline { 2 - 12 } & $A$ & $B$ & $C$ & $R^{2}$ & $10^{2} A R D$ & $10^{3} R M S D$ & $a$ & $b$ & $R^{2}$ & $10^{2} A R D$ & $10^{3} R M S D$ \\
\hline Methanol & -129.96 & 2531.45 & 20.5 & 0.998 & 2.03 & 0.26 & 7.91 & -3750.8 & 0.996 & 3.33 & 0.36 \\
Ethanol & -109.64 & 1561.19 & 17.58 & 0.998 & 2.54 & 0.49 & 8.74 & -3873.4 & 0.999 & 1.95 & 0.3 \\
$n$-Propanol & -129.57 & 4143.14 & 19.68 & 0.998 & 1.76 & 0.63 & 2.57 & -1823.4 & 0.994 & 1.52 & 0.58 \\
$n$-Butanol & 77.6 & -6220.28 & -10.6 & 0.999 & 252 & 0.92 & 6.39 & -2989.5 & 0.999 & 1.29 & 0.4 \\
Chloroform & -116.15 & 2883.04 & 18.18 & 0.998 & 2.39 & 1.88 & 6.08 & -2667.2 & 0.998 & 1.31 & 0.98 \\
Acetonitrile & -98.2 & 3455.62 & 14.73 & 0.997 & 0.61 & 0.55 & 0.71 & -1011.4 & 0.99 & 0.99 & 1.05 \\
Butyl acetate & -113.48 & 4259.55 & 16.96 & 0.998 & 2.69 & 2.2 & 0.37 & -878.49 & 0.984 & 1.25 & 1.17 \\
Ethyl acetate & -123.32 & 4860.94 & 18.22 & 0.997 & 0.43 & 0.19 & -1 & -653.76 & 0.968 & 1.28 & 0.66 \\
Benzene & 177.45 & -10976.2 & -25.27 & 0.996 & 2.25 & 1.12 & 7.39 & -3202.6 & 0.991 & 3.97 & 1.77 \\
Tetrahydrofuran & 141.76 & -7976.67 & -20.68 & 0.993 & 2.53 & 1.94 & 2.84 & -1680.6 & 0.989 & 1.97 & 1.59 \\
\hline
\end{tabular}

${ }^{a} A, B$ and $C$ are parameters of Apelblat model; $a$ and $b$ are parameters of Van't Hoff model;

Table 5 Parameters of Wilson model and NRTL model for tylosin in pure solvent.

\begin{tabular}{|c|c|c|c|c|c|c|c|c|c|c|c|}
\hline \multirow{2}{*}{ Solvents } & \multicolumn{5}{|c|}{ Wilson model } & \multicolumn{6}{|c|}{ NRTL model } \\
\hline & $\Delta \lambda_{12}$ & $\Delta \lambda_{21}$ & $R^{2}$ & $10^{2} A R D$ & $10^{3} \mathrm{RMSD}$ & $\Delta \mathrm{g}_{12}$ & $\Delta \mathrm{g}_{21}$ & $\alpha$ & $R^{2}$ & $10^{2} A R D$ & $10^{3} R M S D$ \\
\hline Methanol & -6156.2 & 332.82 & 0.931 & 24.28 & 3.38 & -11760 & 30168 & 0.3 & 0.998 & 3.1 & 0.33 \\
\hline Ethanol & -17079 & 508.36 & 0.969 & 12.81 & 2.98 & -2273 & -20953 & 1.63 & 0.999 & 2.77 & 0.42 \\
\hline n-Propanol & -13416 & -1162.47 & 0.992 & 8.13 & 3.41 & -4356 & -15589 & 0.89 & 0.996 & 1.84 & 0.77 \\
\hline n-Butanol & -20944 & -373.76 & 0.995 & 5.93 & 2.06 & 63319 & -58013 & 0.04 & 0.999 & 2.71 & 0.46 \\
\hline Chloroform & -28851 & 504.12 & 0.993 & 7.66 & 6.43 & -3154 & -25430 & 1.05 & 0.997 & 2.55 & 1.91 \\
\hline Acetonitrile & -19996 & -1821.32 & 0.997 & 5.58 & 5.28 & 128530 & -118240 & 0.01 & 0.989 & 1.58 & 1.49 \\
\hline Butyl acetate & -17893 & -4824.58 & 0.997 & 5.31 & 5.73 & 144729 & -134897 & 0.01 & 0.985 & 1.61 & 1.67 \\
\hline Ethyl acetate & $1.3 * 10^{12}$ & -4882.22 & 0.988 & 12.21 & 6.04 & 183825 & -158117 & 0.01 & 0.995 & 0.83 & 0.4 \\
\hline Benzene & -26376 & 422.85 & 0.995 & 5.89 & 2.57 & 110424 & -37889 & 0.07 & 0.998 & 3.1 & 1.42 \\
\hline Tetrahydrofuran & -24809 & -684.71 & 0.995 & 7.5 & 7.2 & -32038 & 413596 & 0.03 & 0.997 & 1.71 & 1.15 \\
\hline
\end{tabular}

$\Delta \lambda_{12}$ and $\Delta \lambda_{21}$ are parameters of Wilson model; $\Delta \mathrm{g}_{12}, \Delta \mathrm{g}_{21}$ and are parameters of NRTL model.

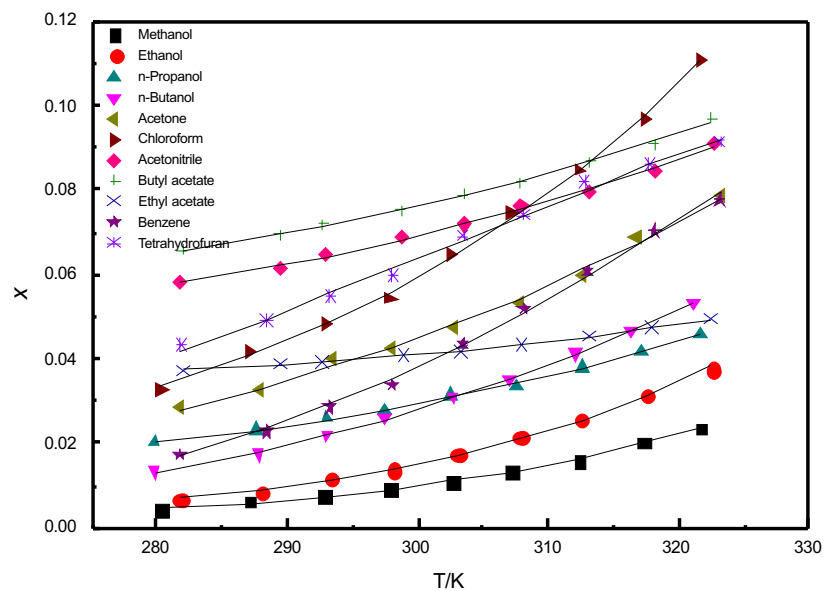

Fig. 4 The measured and calculated mole fraction solubility of tylosin from the modified Apelblat model in pure solvents from at various temperatures. 
Table 6 Parameters of the Apelblat model for tylosin in acetone $\left(1-x_{c}\right)+$ water $\left(x_{c}\right)$ solvents.

\begin{tabular}{lllllll}
\hline Solvents & $A$ & $B$ & $C$ & $R^{2}$ & $10^{2} A R D$ & $10^{3} R M S D$ \\
\hline$x_{c}=0$ & -28.24 & -791.25 & 4.87 & 0.9931 & 2.05 & 1.12 \\
$x_{c}=0.1955$ & -42.25 & 34.37 & 6.83 & 0.9914 & 2.07 & 1.03 \\
$x_{c}=0.3629$ & 107.22 & -6383.22 & -15.64 & 0.9915 & 1.85 & 0.74 \\
$x_{c}=0.4466$ & 55.21 & -3854.6 & -8.02 & 0.9982 & 0.62 & 0.25 \\
$x_{C}=0.5182$ & 48.12 & -3652.47 & -6.93 & 0.9987 & 0.50 & 0.19 \\
$x_{c}=0.6827$ & 70.05 & -4608.74 & -10.35 & 0.9924 & 1.36 & 0.21 \\
$x_{c}=0.7634$ & 109.34 & -6437.15 & -16.23 & 0.9941 & 1.16 & 0.30 \\
$x_{c}=0.8288$ & 56.65 & -4289.54 & -8.28 & 0.9951 & 1.11 & 0.11 \\
$x_{c}=0.8827$ & 62.29 & -4701.23 & -9.19 & 0.9947 & 1.48 & 0.05 \\
$x_{c}=0.9281$ & -250.46 & 12231.75 & 35.51 & 0.9931 & 1.46 & 0.01 \\
$x_{c}=0.9667$ & -16.94 & 2254.3 & 0.24 & 0.9922 & 2.33 & 0.00 \\
$x_{c}=1$ & -95.81 & 6680.6 & 11.27 & 0.9965 & 3.11 & 0.00
\end{tabular}

${ }^{a} A, B$ and $C$ are parameters of Apelblat model;

$x_{c}$ is initial composition of water in acetone+water mixture solvent.

Table 7 Parameters of the C/ R-K model for tylosin in acetone $\left(1-x_{c}\right)+$ water $\left(x_{c}\right)$ solvents.

\begin{tabular}{lcccccccr}
\hline $\mathrm{T} / \mathrm{K}$ & $B_{0}$ & $B_{1}$ & $B_{2}$ & $B_{3}$ & $B_{4}$ & $R^{2}$ & $10^{2} A R D$ & $10^{3} R M S D$ \\
\hline 281.15 & -3.5924 & -0.5511 & 4.7253 & -11.3427 & 3.4646 & 0.996 & 15.39 & 0.54 \\
288.15 & -3.4048 & -0.6102 & 4.4083 & -10.5526 & 2.9689 & 0.996 & 25.19 & 0.68 \\
293.15 & -3.2744 & -0.6178 & 3.9287 & -9.5583 & 2.4072 & 0.995 & 33.96 & 0.8 \\
298.15 & -3.1468 & -0.5982 & 3.2466 & -8.2068 & 1.6612 & 0.995 & 44.15 & 0.94 \\
303.15 & -3.022 & -0.5454 & 2.3251 & -6.4188 & 0.6782 & 0.995 & 55.58 & 1.08 \\
308.15 & -2.8999 & -0.4615 & 1.181 & -4.2244 & -0.5275 & 0.995 & 68.33 & 1.22 \\
313.15 & -2.7803 & -0.3376 & -0.2537 & -1.4757 & -2.0516 & 0.994 & 81.79 & 1.36 \\
318.15 & -2.6633 & -0.1848 & -1.89 & 1.6387 & -3.7771 & 0.995 & 95.57 & 1.5 \\
323.15 & -2.55 & 0.0003 & -3.75 & 5.1692 & -5.7357 & 0.995 & 110.19 & 1.65 \\
\hline \multicolumn{7}{c}{$B . B$} & $B, B$ and $B$ are parameters of $C / R-K$ model
\end{tabular}

Table 8 Parameters of the Jouyban-Acree model for tylosin in acetone $\left(1-x_{c}\right)+$ water $\left(x_{c}\right)$ solvents.

\begin{tabular}{lllllll}
\hline System & $A_{0}$ & $A_{1}$ & $A_{2}$ & $A_{3}$ & $A_{4}$ & $A_{5}$ \\
\hline \multirow{3}{*}{ Aectone+water } & 267.6 & -14032.2 & -38.45 & -279.91 & 14273.35 & 162.25 \\
& $A_{6}$ & $A_{7}$ & $A_{8}$ & $R^{2}$ & $A R D$ & $R M S D$ \\
& -929 & -368.21 & 40.69 & 0.994 & 56.46 & 2.54 \\
\hline
\end{tabular}

${ }^{\mathrm{a}} A_{0}, A_{1}, A_{2}, A_{3}, A_{4}, A_{5}, A_{6}, A_{7}$ and $A_{8}$ are parameters of Jouyban-Acree model. 


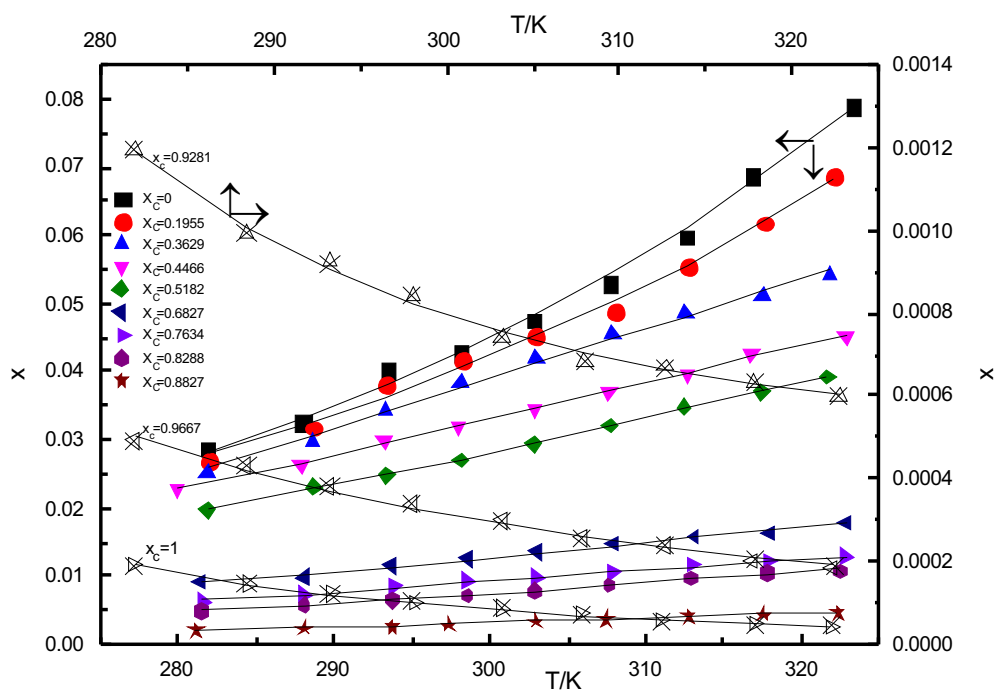

Fig. 5 The measured and calculated mole fraction solubility of tylosin from the modified Apelblat model in acetone $\left(1-x_{c}\right)+$ water $\left(x_{c}\right)$ solvents from at various temperatures.

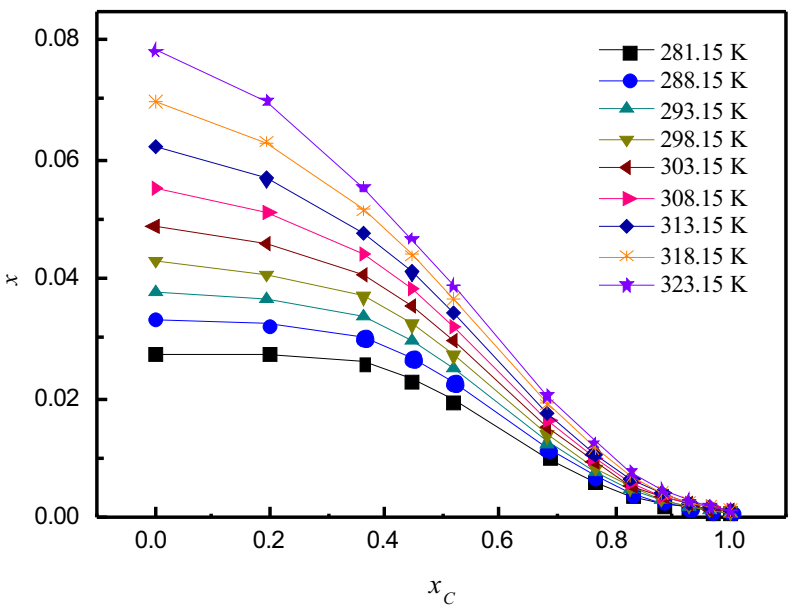

Fig. 6 The measured and calculated mole fraction solubility of tylosin from the C/R-K model in acetone $\left(1-x_{c}\right)+$ water $\left(x_{c}\right)$ solvents from at various temperatures.

\subsection{Thermodynamic properties for the solution}

The research of thermodynamic properties for dissolution process is necessary to analyzing and optimization design for industry application. $\Delta_{\text {soo }} H^{o}$ is defined as standard dissolution enthalpy, $\Delta_{\text {so }} S^{o}$ is defined as standard dissolution entropy, and $\Delta_{s o l} G^{o}$ is defined as standard dissolution Gibbs energy change. $\Delta_{s o l} H^{\circ}, \Delta_{\text {sol }} S^{o}$ and $\Delta_{s o l} G^{o}$ of solution of tylosin dissolution process in different solvents can be calculated with Eq. (21), Eq. (22) and Eq. $(23)^{24,25}$ by Gibbs-Duhem equation, Van't Hoff equation and modified Apelblat model. $\zeta_{H}$ and $\zeta_{T S}$ are defined as the comparison of the relative contribution of $\Delta_{s o l} H^{o}$ and $\Delta_{s o l} S^{o}$ to $\Delta_{s o l} G^{o}$ in dissolution process process. $^{26-30}$

$$
\begin{gathered}
\Delta_{\mathrm{sol}} H^{\mathrm{o}}=R T\left(C-\frac{B}{T}\right) \\
\Delta_{\mathrm{sol}} S^{\mathrm{o}}=R(A+C+C \ln T) \\
\Delta_{\mathrm{sol}} G^{\mathrm{o}}=-R T(A+B / T+C \ln T)
\end{gathered}
$$

$$
\begin{gathered}
S_{H}=\frac{\left|\Delta_{s o l} H^{0}\right|}{\left|\Delta_{s o l} H^{0}\right|+\left|T \Delta_{s o l} S^{0}\right|} \times 100 \\
\varsigma_{T S}=\frac{\left|T \Delta_{s o l} S^{0}\right|}{\left|\Delta_{s o l} H^{0}\right|+\left|T \Delta_{s o l} S^{0}\right|} \times 100
\end{gathered}
$$

where $R$ is the universal gas constant $\left(8.314 \mathrm{~J} \cdot \mathrm{mol}^{-1} \cdot \mathrm{K}^{-1}\right)$, three parameters of $A, B$ and $C$ are from modified Apelblat. $T$ is $298.15 \mathrm{~K}$.

The values of $\Delta_{\text {sol }} H^{\circ}, \Delta_{\text {sol }} S^{\circ}$ and $\Delta_{\text {sol }} G^{o}$ were listed in Tables 9 and 10 together with $\zeta_{H}$ and $\zeta_{T s}$. It indicated that $\Delta_{s o l} H^{o}, \Delta_{s o l} S^{o}$ and $\Delta_{s o l} G^{o}$ values of tylosin dissolution process were all positive in solvents except for $x_{c}>0.8827$ mixture solvents. $\Delta_{s o l} H^{o}>0$ proved that the dissolving process of tylosin in solvents was expressed as endothermic process. $\Delta_{\text {sol }} S^{\circ}>0$ showed it was an entropy-drives in dissolving process of tylosin. Further, $\zeta_{H}>0.55$ showed that $\Delta_{\text {sol }} H^{o}$ was the main contributor to $\Delta_{s o l} G^{o}$ during the dissolution. Otherwise, $\zeta_{T S}>0.55$ showed that $\Delta_{s o l} S^{o}$ was the main contributor to $\Delta_{s o l} G^{o}$.

\section{Conclusions}


Table 9 Thermodynamic functions relative to dissolution process of tylosin in pure solvents.

\begin{tabular}{lllllc}
\hline \multirow{2}{*}{ Systems } & $\triangle_{\text {sol }} H^{o}$ & $\triangle_{\text {sol }} S^{o}$ & $\triangle_{\text {sol }} G^{o}$ & $\zeta_{H}$ & $\zeta_{T S}$ \\
\cline { 2 - 6 } & $\mathrm{kJ} \cdot \mathrm{mol}^{-1}$ & $\mathrm{~J} \cdot \mathrm{mol}^{-1} \cdot \mathrm{K}^{-1}$ & $\mathrm{~kJ} \cdot \mathrm{mol}^{-1}$ & $\%$ & $\%$ \\
\hline Methanol+tylosin & 29.77 & 61.03 & 11.57 & 62.06 & 37.94 \\
Ethanol+tylosin & 30.60 & 67.37 & 10.51 & 60.37 & 39.63 \\
n-Propanol+tylosin & 14.34 & 18.61 & 8.79 & 72.09 & 27.91 \\
$n$-Butanol+tylosin & 25.44 & 54.92 & 9.07 & 60.84 & 39.16 \\
Chloroform+tyl osin & 21.10 & 46.66 & 7.18 & 60.26 & 39.74 \\
Acetonitrile+tylosin & 7.78 & 3.79 & 6.65 & 87.33 & 12.67 \\
Butyl acetate+tylosin & 6.63 & 0.92 & 6.35 & 96.01 & 3.99 \\
Ethyl acetate + tylosin & 4.75 & 10.72 & 7.95 & 59.78 & 40.22 \\
Benzene+tylosin & 28.62 & 68.19 & 8.29 & 58.46 & 41.54 \\
Tetrahydrofuran+tylosin & 15.06 & 27.05 & 6.99 & 65.12 & 34.88 \\
\hline
\end{tabular}

${ }^{a} \Delta_{s o l} H^{o}, \Delta_{s o l} S^{o}$ and $\Delta_{s o l} G^{o}$ are the standard molar enthalpy, standard molar entropy and standard molar Gibbs energy change of solution of tylosin in different solvents;

The $\zeta_{H}$ and $\zeta_{T S}$ represent the comparison of the relative contribution to the standard Gibbs energy by enthalpy and entropy in the solution process, respectively.

Table 10 Thermodynamic functions relative to dissolution process of tylosin in acetone $\left(1-x_{c}\right)+$ water $\left(x_{c}\right)$ solvents.

\begin{tabular}{lccccc}
\hline \multirow{2}{*}{ Systems } & $\triangle_{\text {sol }} H^{o}$ & $\triangle_{\text {sol }} S^{o}$ & $\triangle_{\text {Sol }} G^{o}$ & $\zeta_{H}$ & $\zeta_{T S}$ \\
\cline { 2 - 6 } & $\mathrm{kJ} \cdot \mathrm{mol}^{-1}$ & $\mathrm{~J} \cdot \mathrm{mol}^{-1} \cdot \mathrm{K}^{-1}$ & $\mathrm{~kJ} \cdot \mathrm{mol}^{-1}$ & $\%$ & $\%$ \\
\hline$x_{c}=0$ & 18.65 & 36.40 & 7.80 & 63.22 & 36.78 \\
$\mathrm{xc}=0.1955$ & 16.64 & 29.05 & 7.98 & 65.77 & 34.23 \\
$x_{c}=0.3629$ & 14.30 & 20.53 & 8.18 & 70.03 & 29.97 \\
$x_{c}=0.4466$ & 12.17 & 12.43 & 8.46 & 76.65 & 23.35 \\
$x_{c}=0.5182$ & 13.19 & 14.18 & 8.96 & 75.72 & 24.28 \\
$x_{c}=0.6827$ & 12.66 & 6.07 & 10.85 & 87.5 & 12.5 \\
$x_{c}=0.7634$ & 13.29 & 5.30 & 11.71 & 89.36 & 10.64 \\
$x_{c}=0.8288$ & 15.14 & 9.93 & 12.18 & 83.65 & 16.35 \\
$x_{c}=0.8827$ & 16.31 & 6.14 & 14.47 & 89.9 & 10.1 \\
$x_{c}=0.9281$ & -13.67 & -104.99 & 17.63 & 30.4 & 69.6 \\
$x_{c}=0.9667$ & -18.15 & -127.48 & 19.86 & 32.32 & 67.68 \\
$x_{c}=1$ & -27.61 & -169.16 & 22.82 & 35.38 & 64.62 \\
\hline
\end{tabular}

New experimental results for solubility of tylosin in different solvents were investigated at temperature from 279.75 to $323.15 \mathrm{~K}$. It could be seen that the solubility of tylosin in chloroform was the highest and followed by butyl acetate, acetonitrile, tetrahydrofuran, acetone, benzene, n-butanol, ethyl acetate, n-propanol, ethanol, methanol and water. Solubility of tylosin gradually decreased with water increasing in water+acetone mixture solvents. Data fitting results showed the modified Apelblat model agreed litter better with experimental data than Van't Hoff model, Wilson model NRTL model in pure solvents, and $\mathrm{C} / \mathrm{R}-\mathrm{K}$ model, Jouyban Acree model in acetone+water solvents according with $A R D, R M S D$ and $R^{2}$. The calculated data of $\Delta_{\text {sol }} H^{\circ}, \Delta_{\text {sol }} S^{\circ}$, $\Delta_{s o l} G^{o}, \zeta_{H}$ and $\zeta_{T S}$ indicated that solution process of tylosin in solvents was expressed as endothermic process and an entropy-drives process. Dilution crystallization process will be selected to separate and purify for tylosin according with experimental results.

\section{Conflict of interest}

There are no conflicts to declare.

\section{Acknowledgements}

The work is financially supported by Project of Doctoral Fund in Henan University of Technology (2016BS025), Program for Science \& Technology in Henan University of Technology (2017QNJH29, 2017RCJH09) and China Scholarship Council (CSC). 


\section{References}

1. J. M. McGuire, W. S. Boniece, C. E. Higgens, M. M. Hoehn,W. M. Stark, J. Westhead and R. N. Wolfe, Antibiotics and Chemotherapy, 1961, 11, 320-327.

2. H. A. Kirst, Progress in Medicinal Chemistry, 1994, 31, 265-295.

3. K. Kumar, S. C. Gupta , Y. Chander and A. K .Singh, Adv. Agron., 2005, 87,1-54.

4. Y. M. Shen, Z. F. Liu, T. Li and B. Z. Ren, J. Chem. Thermodyn., 2015, 80, 128-134.

5. X. M. Jiang, Y. H. Hu, Z. B. Meng, W. G. Yang and F. Shen, Fluid Phase Equilib., 2013, 341, 7-11.

6. J. H. Hildebrand, J. M. Prausnitz and R. L. Scott, Regular and Related Solutions. Van Nostrand Reinhold Co., New York.1970.

7. Y. Li , F. A.Wang, L. Xu, H. Jin and B. Z. Ren, Fluid Phase Equilib., 2010, 298, 246-252.

8. R. L. Hamill, M. E.Haney, J. M. Mcguire and M. C. Stamper, US 3178341, 1965.

9. A. Apelblat and E. Manzurola, J. Chem. Thermodyn.,1997, 29, 1527-1533.

10. A. Apelblat and E. Manzurola, J. Chem. Thermodyn.,1999, 31, 85-91.

11. J. J. Zhi, Q. Liu, T. Li and B. Z. Ren, J. Chem. Eng. Data., 2016, 61, 2052-2061.

12. Y. M. Shen, Z. F. Liu, J. J. Zhi, T. Li and B. Z. Ren, J. Mol. Liq., 2015, 203, 131-136.

13. S. J. Han, Chemical Phase Equilibrium. Beijing: China Petrochemical Press, 1991.

14. F. A. Wang and Y. L. Jiang, Molecular Thermodynamics and Chromatographic Retention.Beijing : Meteorology Press, 2001.

15. G. M. Wilson, J. Am. Chem. Soc.,1964, 86, 127-130.

16. X. Z. Chen, Z. Y. Cai and W. M. Hu, Chemical Engineering Thermodynamics. Beijing : Chemical Industry Press, 2008.
17. H. Renon and J. M. Prausnitz, Ind. Eng. Chem. Process Des. Dev, 1969, 8, 413-419.

18. B. D. Souza, L. Keshavarz, R. R. E. Steendam, O. C. Dennehy, D. Lynch, S. G. Collins, H. A. Moynihan, A. R. Maguire and P. J. Frawley, J. Chem. Eng. Data., 2018, 63, 1419-1428.

19. W. E. Acree, Jr. Thermochim. Acta.,1992, 198, 71-79.

20. A. Jouyban, J. Pharm. Sci., 2008, 11, 32-58.

21. D.Y. Li, H. X. Hao, B. B. Fang, N. Wang, Y. N. Zhou, X. Huang and Z. Wang, Fluid Phase Equilib., 2018, 461, 57-69.

22. H. Zhang, Z. K Liu, X. P. Huang and Q. Zhang, J. Chem. Eng. Data., 2018, 63, 233-245.

23. A. Jouyban, F. Martinez and W. E. Acree, Jr. J. Chem. Eng. Data., 2017, 62 $1153-1156$

24. C. L. Zhang, F. A. Wang and Y. Wang, J. Chem. Eng. Data., 2007, 52, $1563-1566$.

25. T. Li, Z. X. Jiang, F. X Chen and B. Z. Ren. Fluid. Phase. Equilibria.,2012, 333, 13-17.

26. G. Wang, Y. L.Wang, X. W. Hu, Y. G. Ma and H. X. Hao, Fluid. Phase. Equilibr, 2014, 361, 223-228.

27. X. Liu, Y. H. Hu, M. M. Liang,Y. L. Li, J. J. Yin and W. G. Yang, Fluid. Phase. Equilib., 2014, 367, 1-6.

28. H. Buchowski, A. Ksiazcak and S. Pietrzyk, J. Phys. Chem., 1980, 84, 975-979.

29. J. Fang, M. J. Zhang, P. P. Zhu, J. B. OuYang, J. B. Gong, W. Chen and F. X. $\mathrm{Xu}, J$. Chem.Thermodyn., 2015, 85, 202-209.

30. C. Cheng, C. Yang, L. Meng, J. Wang, G. B. Yao and H. K. Zhao, J. Chem. Thermodyn., 2016, 97, 158-166.

Publisher's Note Engineered Science Publisher remains neutral with regard to jurisdictional claims in published maps and institutional affiliations. 